\title{
The relationship between fasting plasma glucose and MPO in patients with acute coronary syndrome
}

\author{
Xiangyu Zhang, Lini Dong, Qiong Wang and Xiaomei Xie*
}

\begin{abstract}
Background: Inflammation plays a critical role in the progression of atherosclerosis, and hyperglycemia is a common feature in patients with ACS. We investigated the relationship between fasting plasma glucose (FPG) levels and the levels of the inflammatory factor, myeloperoxidase (MPO), in patients with acute coronary syndrome (ACS).

Method: A total of 85 patients with no prior history of diabetes mellitus were recruited. The patients were divided into three groups based on their FPG levels as follows: group A, FPG $<5.6 \mathrm{mmol} / /$; group B, $5.6 \mathrm{mmol} / \mathrm{l} \leq \mathrm{FPG}<$ $6.1 \mathrm{mmol} / \mathrm{l}$; and group C, FPG $\geq 6.1 \mathrm{mmol} / \mathrm{l}$. The FPG concentrations and plasma MPO levels were determined, coronary angioplasty was performed, and the Gensini scores were used to evaluate the severity of the coronary lesion. The MPO expression in peripheral blood mononuclear cells (PBMCs) in patients with ACS was determined using western blot analysis.

Result: The results demonstrated that the levels of FPG were significantly and positively correlated with plasma MPO levels, Gensini scores, high sensitive C reaction protein(hs-CRP)levels, leukocyte and neutrophils count. In multivariate regression analyses the FPG levels were positively correlated with plasma MPO levels, Gensini score and hs-CRP. The plasma MPO levels in the group C [68.68(52.62-91.88) $\mathrm{U} / \mathrm{L}]$ were significantly higher than in the group A [63.04(26.18-97.75) U/L] and group B [58.22(23.95-89.54) U/L]. The plasma hs-CRP concentrations are also higher in group C [42.28 (0.31-169.40) mg/L] than in the group A [12.51(0.28-176.25) mg/L] and group B [14.7 (0.14-89.68) $\mathrm{mg} / \mathrm{L}]$.
\end{abstract}

Conclusion: This study demonstrates that FPG values are positively correlated with plasma MPO levels, suggesting MPO may play a role in the proatherogenesis of high FPG.

\section{Background}

Increased plasma glucose is a common occurrence during the first few hours of acute coronary syndrome (ACS), not only in diabetics, but also in non-diabetic patients [1]. Epidemiological studies indicated that hyperglycemia plays an independent role in cardiovascular disease [2]. Hyperglycemia, regardless of diabetic status, remains to be a risk factor for the short-term mortality of patients with acute myocardial infarction and treated with percutaneous coronary intervention [3-5], whereas fasting plasma glucose (FPG) levels are a better predictor of adverse outcomes in ACS patients during hospitalization than the admission

\footnotetext{
* Correspondence: marrie2088@sina.com

Department of Geriatrics, Second Xiangya Hospital of Central South University, Changsha, Hunan 410011, P. R. China
}

plasma glucose (APG) level [6]. Several studies showed that the proatherogenic role is related to the production of reactive oxygen species [6-8] and platelet dysfunction [5]. However, the direct influence, if any, of hyperglycemia, on ACS patients remains unclear.

Myeloperoxidase (MPO) is a type of leukocyte enzyme that is promptly released after activation. MPO and its oxidant products have been identified in atherosclerotic plaques, promoting a number of pathological events that participate in plaque formation and rupture $[9,10]$. In clinical studies, elevated MPO levels are associated with an adverse prognosis and the occurrence of major cardiovascular events [11-13]; therefore, MPO is also a key inflammatory factor in the course of the plaque formation and rupture, similar to CRP. To our knowledge, there is 
no available study about the relationship between the fasting plasma glucose level (FPG) and MPO in patients with ACS. The objective of this study is to determine whether the changes in FPG influence MPO.

\section{Methods \\ Study subjects}

A total of 85 patients with acute coronary syndrome, including acute myocardial infarction and unstable angina, and no prior history of diabetes mellitus were recruited. The patients were divided into three groups based on their FPG levels as follows: group A ( $n=33), \mathrm{FPG}<5.6 \mathrm{mmol} / \mathrm{l}$; group B $(n=23), 5.6 \mathrm{mmol} / \mathrm{l} \leq \mathrm{FPG}<6.1 \mathrm{mmol} / \mathrm{l}$; and group C ( $n=29)$, FPG $\geq 6.1 \mathrm{mmol} / \mathrm{l}$. Unstable angina was defined as ischemic chest pain at rest, accompanied by transient ST-T segment depression and/or T-wave inversion within the next $24 \mathrm{~h}$. The diagnosis of acute myocardial infarction was based on a history of ischemic chest pain $>30$ min, characteristic ECG changes, and an increase of creatine kinase activities to at least twice the normal upper level within $24 \mathrm{~h}$ of the pain. The exclusion criteria includes body temperature $>38{ }^{\circ} \mathrm{C}$; inflammatory diseases, such as infections, malignancies, and autoimmune diseases; human immunodeficiency virus (HIV); impaired liver function; renal failure; serum total cholesterol concentration $>7.0 \mathrm{mmol} / \mathrm{L}$; hemoglobin A1c (HbA1c) above $6.5 \%$; and recent major surgery. Experienced interventional cardiologists performed all revascularization procedures. Coronary angioplasty was performed and stent was implanted if necessary and the Gensini scores were used to evaluate the severity of the coronary lesion. The Institutional Ethics Committee of the 2nd Xiangya Hospital of Central South University approved this study. All of the subjects have provided written informed consent.

\section{Biochemical analysis}

Using standard automated enzymatic methods, a Hitachi 912 automated analyzer, and reagents from the Kamiya Biomedical Company, the serum triglycerides (TG), total cholesterol (TC), high-density lipoprotein cholesterol (HDL-C), high sensitive $\mathrm{C}$ reaction protein (hs-CRP) and fasting plasma glucose levels (FPG) (FPG was determined after $>8 \mathrm{~h}$ of fasting) and liver and renal functions were determined at the central chemistry laboratory of our hospital. The LDL-C level was calculated using the Friedwald formula, and the plasma MPO levels were measured with an ELASA kit (Jingmei BioTech Co.Ltd).

\section{Peripheral blood mononuclear cells preparation}

Peripheral blood mononuclear cells (PBMCs) isolation was performed using the Ficoll-Hypaque densitygradient centrifugation method from the patients with ACS. After centrifugation, buffy coats were collected and washed in phosphate-buffered saline (PBS; Gibco,
Darmstadt, Germany) for 3 times and suspended at a concentration of $2 \times 10^{6}$ cells per milliliter with complete RPMI 1640 medium containing $2 \mathrm{mM}$ l-glutamine, 100 $\mathrm{U} / \mathrm{mL}$ penicillin, $100 \mu \mathrm{g} / \mathrm{mL}$ streptomycin, $0.05 \mathrm{mM} \mathrm{2-}$ mercaptoethanol, supplemented with $10 \%$ fetal calf serum (Gibco, Germany). Cell viability was evaluated using $95 \%$ by the trypan blue exclusion test. Cells were collected for MPO protein assays.

\section{Detection of MPO expression in PBMCs by western blot}

To determine the expression of MPO in human PBMCs, immunoblot analysis was performed. Cells $\left(2 \times 10^{7}\right)$ were lysed with Triton lysis buffer (50 mM Tris-HCL, $\mathrm{pH} 8.0$ containing $150 \mathrm{mM} \mathrm{NaCl}, 1 \%$ Ttriton X-100, $0.02 \%$ soldium azide, $10 \mathrm{mM}$ EDTA, $10 \mu \mathrm{g} / \mathrm{ml}$ aprotinin, and1 $\mu \mathrm{g} /$ $\mathrm{ml}$ aminoethyl benzenesulfonyl fluoride). Protein concentrations were determined by Bradford assay. One hundred micrograms of protein from the cell lysates were loaded onto a $7.5 \%$ SDS-PAGE gel. After electronphoresis, the SDS-PAGE separated proteins were transferred to a nitrocellulose membrane (Amersham Pharmacia Biotech). The membrane was blocked with $2.5 \%$ nonfat milk in PBS and incubated with rabbit antibody against human MPO (1:200 dilution) in PBS for $2 \mathrm{~h}$. Then the membrane was incubated with goat anti-rabbit IgG conjugated with horseradish peroxidase (Santa Cruz, Biotechnology, CA, USA) at 1:1000 in PBS for $1 \mathrm{~h}$. Blots were processed using an ECL kit (Santa Cruz) and exposed to X-ray film.

\section{Statistical analyses}

All data were tested for normal distribution with Kolmogorov-Smirnov test and for homogeneity of variances with Levene's test. Data are expressed as mean \pm SD or median for parametric and nonparametric data respectively, categorical variables as numbers and percentages. The baseline characteristics of group categorized by FPG level were compared by use of ANOVA for continuous variables and by Kruskal-Wallis Test followed by MannWhitney nonparametric test for noncontinuous variables. Univariate and multivariate analyses of the effects of the factors on FPG were performed with linear regression analyses. Differences were considered statistically significant at the 2 -sided $P<0.05$ level. Statistical analyses were performed with SPSS statistical software (18.0).

\section{Results}

\section{Baseline characteristics of the patients}

The clinical characteristics of ACS were shown in Table 1. Leukocyte count in the group B and C were more than in the group A. The Gensini scores in the group B and $\mathrm{C}$ were significantly higher than in the group A. There were no statistically significant differences between the three groups in the other patient's characteristics, medication histories and smoking. 
Table 1 Baseline characteristics of the patients

\begin{tabular}{llll}
\hline & Group A & Group B & Group C \\
& $N=33$ & $N=23$ & $N=29$ \\
\hline Age (year) & $63 \pm 10$ & $68 \pm 9$ & $67 \pm 10$ \\
Male/female(n) & $18 / 15$ & $12 / 11$ & $20 / 9$ \\
BMI(kg/m²) & $23.6 \pm 0.4$ & $23.5 \pm 0.52$ & $23.6 \pm 0.3$ \\
Smoking, n (\%) & $20(61)$ & $13(56)$ & $19(69)$ \\
SBP(mmHg) & $130 \pm 4$ & $127 \pm 3$ & $128 \pm 3$ \\
DBP(mmHg) & $76 \pm 2$ & $74 \pm 2$ & $75 \pm 2$ \\
Leukocyte ( 109/L) & $5.5 \pm 1.95$ & $6.7 \pm 1.87^{*}$ & $7.18 \pm 2.10^{*}$ \\
Creatinine ( $\mu$ mol/L) & $109.7 \pm 9.6$ & $99.38 \pm 4.5$ & $99.65 \pm 5.88$ \\
TG(mmol/L) & $2.05 \pm 0.25$ & $1.85 \pm 0.22$ & $2.8 \pm 0.90$ \\
TC(mmol/L) & $5.05 \pm 0.18$ & $4.54 \pm 0.18$ & $4.8 \pm 0.12$ \\
LVEF (\%) & $0.59 \pm .03$ & $0.58 \pm 0.02$ & $0.57 \pm 0.03$ \\
Gensini score & $29.7(21.0-56.2)$ & $35.1(23.8-55.0)^{*}$ & $43.6(22.0-56.0)^{*}$, ** \\
Medications, $\mathrm{n}(\%)$ & & & \\
Aspirin & $13(39)$ & $10(43)$ & $11(37)$ \\
B-blocker & $15(45)$ & $11(47)$ & $14(48)$ \\
ACEl/ARB & $21(67)$ & $16(76)$ & $20(68)$ \\
CCB & $7(22)$ & $4(19)$ & $5(17)$ \\
Nitrate & $21(63)$ & $16(69)$ & $18(62)$ \\
Statin & $10(30)$ & $8(34)$ & $11(37)$ \\
\hline Values a & &
\end{tabular}

Values are presented as mean \pm SD. or $n(\%)$ or median

$B M I$ body mass index; SBP systolic blood pressure; $D B P$ diastolic blood pressure; TG triglyceride; TC total cholesterol; $L V E F$ left ventricular ejection fraction; $A C E I$ angiotensin-converting enzyme inhibitors; $A R B$ angiotensin II receptor blockers; $C C B$ calcium channels blockers

${ }^{*} P<0.05$ when compared with Group $A ;{ }^{* *} P<0.05$ when compared with Group B

\section{Correlation analysis FPG with other parameters}

Spearman correlation analyses were performed to assess the relationships at baseline in all patients. The results demonstrate that FPG were significantly and positively correlated with plasma MPO levels, Gensini scores, hsCRP levels, leukocyte count and neutrophils count (Table 2). Multivariate regression analyses were further performed to assess the relationships between the FPG with these variables and showed that the FPG levels were still positively correlated with plasma MPO levels, Gensini score and hs-CRP (Table 3).

\section{Effects of FPG on plasma MPO levels and hs-CRP in patients}

As shown in Figs. 1 and 2, the plasma MPO levels in the group C [68.68(52.62-91.88) U/L] were significantly higher than in the group A [63.04(26.18-97.75) U/L] and group B [58.22(23.95-89.54) U/L]. The plasma hs-CRP concentrations are also higher in group $\mathrm{C}$ [42.28 (0.31$169.40) \mathrm{mg} / \mathrm{L}]$ than in the group A $[12.51(0.28-176.25)$ $\mathrm{mg} / \mathrm{L}]$ and group B [14.7 (0.14-89.68) $\mathrm{mg} / \mathrm{L}]$. There were
Table $\mathbf{2}$ Correlation between the FPG with other variables in the patients

\begin{tabular}{lcl}
\hline Variables & $r$ & $p$ \\
\hline MPO & 0.492 & 0.000 \\
Gensini score & 0.568 & 0.000 \\
Leukocyte count & 0.353 & 0.001 \\
Neutrophil count & 0.220 & 0.048 \\
hs-CRP & 0.453 & 0.001 \\
TG & -0.37 & 0.734 \\
TC & 0.014 & 0.900 \\
Creatinine & 0.021 & 0.852 \\
LVEF & -0.228 & 0.146 \\
SBP & -0.095 & 0.397 \\
DBP & -0.07 & 0.950 \\
Age & -0.158 & 0.160 \\
Gender & -0.068 & 0.546 \\
\hline
\end{tabular}

MPO myeloperoxidase; $h s$-CRP high sensitive $C$ reaction protein; other abbreviations are as shown in Table 1

no significantly differences in these two parameters between in the group A and B.

\section{Effect of FPG on MPO expression of PBMCs in patients}

MPO expression in PBMCs was detected by western blot analysis. As shown in Fig. 3, it was found that FPG had no effect on MPO expression in PBMCs from patients with ACS.

\section{Discussion}

The blood glucose concentration is closely associated with cardiovascular diseases and a greater number of adverse events. The mechanism by which glycemia is associated with higher mortality remains unclear. Several studies showed that hyperglycemia is associated with increased coagulability and oxidative stress and promotes apoptosis in the rat heart [14-17]. The main finding of present study is that in patients with ACS, the FPG concentrations are positively correlated with plasma MPO levels. Furthermore, the plasma MPO levels and hs-CRP concentrations significantly increase in the highest FPG group (group C). These results demonstrate that high FPG may promote an

Table 3 Multiple stepwise regression analysis of the correlation of FPG with hs-CRP, MPO and Gensini score

\begin{tabular}{lcclll}
\hline $\begin{array}{l}\text { Independent } \\
\text { variable }^{\mathrm{a}}\end{array}$ & $\begin{array}{l}\text { Partial } \\
\text { regression } \\
\text { coefficient }\end{array}$ & $\begin{array}{l}\text { Standard } \\
\text { error }\end{array}$ & $\begin{array}{l}\text { Standardized } \\
\text { regression } \\
\text { coefficient }\end{array}$ & T & $P$ \\
\hline Constant & 2.339 & 0.615 & & 3.802 & 0.000 \\
Hs-CRP & 0.014 & 0.004 & 0.306 & 3.588 & 0.001 \\
MPO & 0.024 & 0.005 & 0.346 & 4.439 & 0.000 \\
Gensini score & 0.051 & 0.015 & 0.279 & 3.359 & 0.001 \\
\hline
\end{tabular}




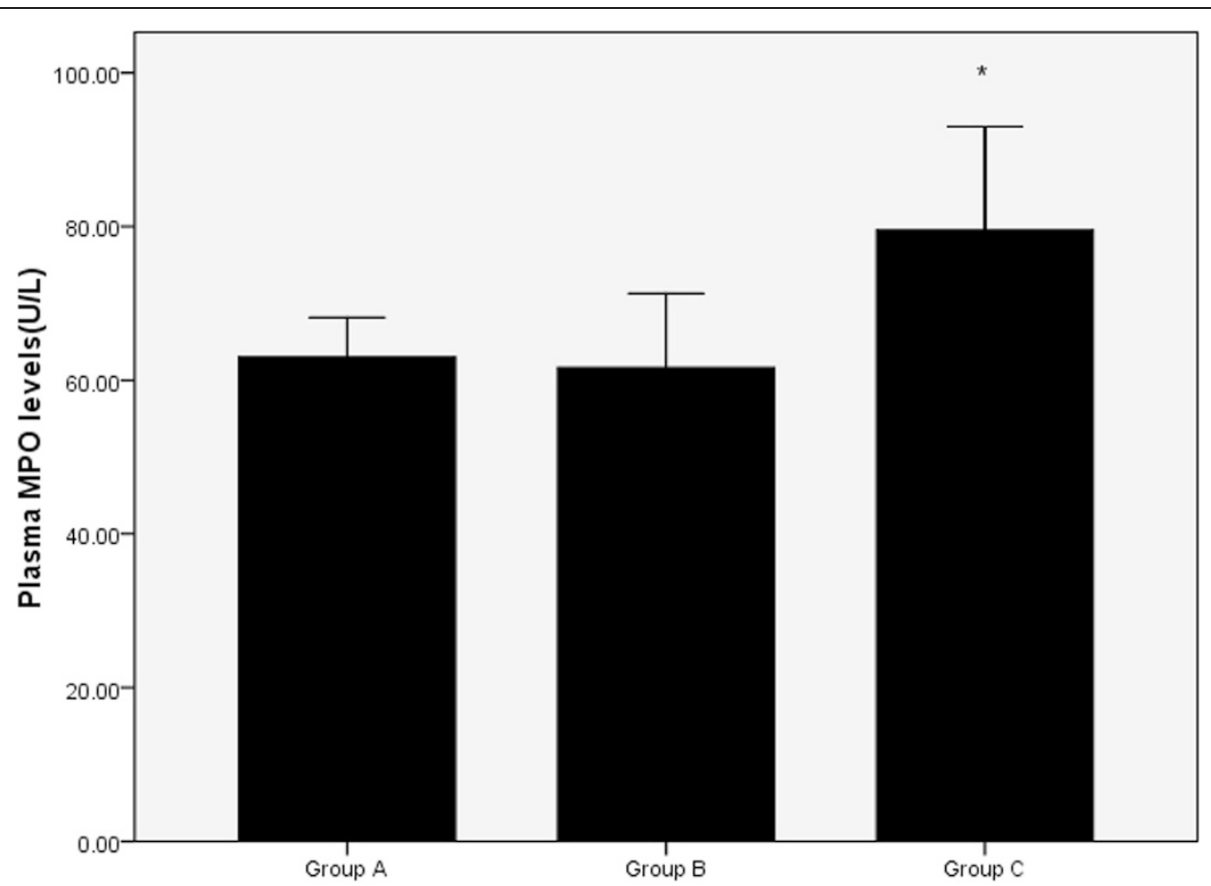

Fig. 1 The plasma MPO levels in the three groups. ${ }^{*} p<0.05$ when compared to Group A or Group B

inflammatory reaction during ACS, leading to an increase of plasma MPO levels, and finally causing plaque formation and rupture. As we all known, PBMCs are more important in atherosclerosis. However, the present study did not shown the significant effects of FPG on the MPO expression of PBMCs, indicating that FPG may play a role in the acute inflammatory reaction in patients with ACS via another type of leukocyte (maybe neutrophil). Being the most abundant leukocyte in the circulation, neutrophil received little attention in the

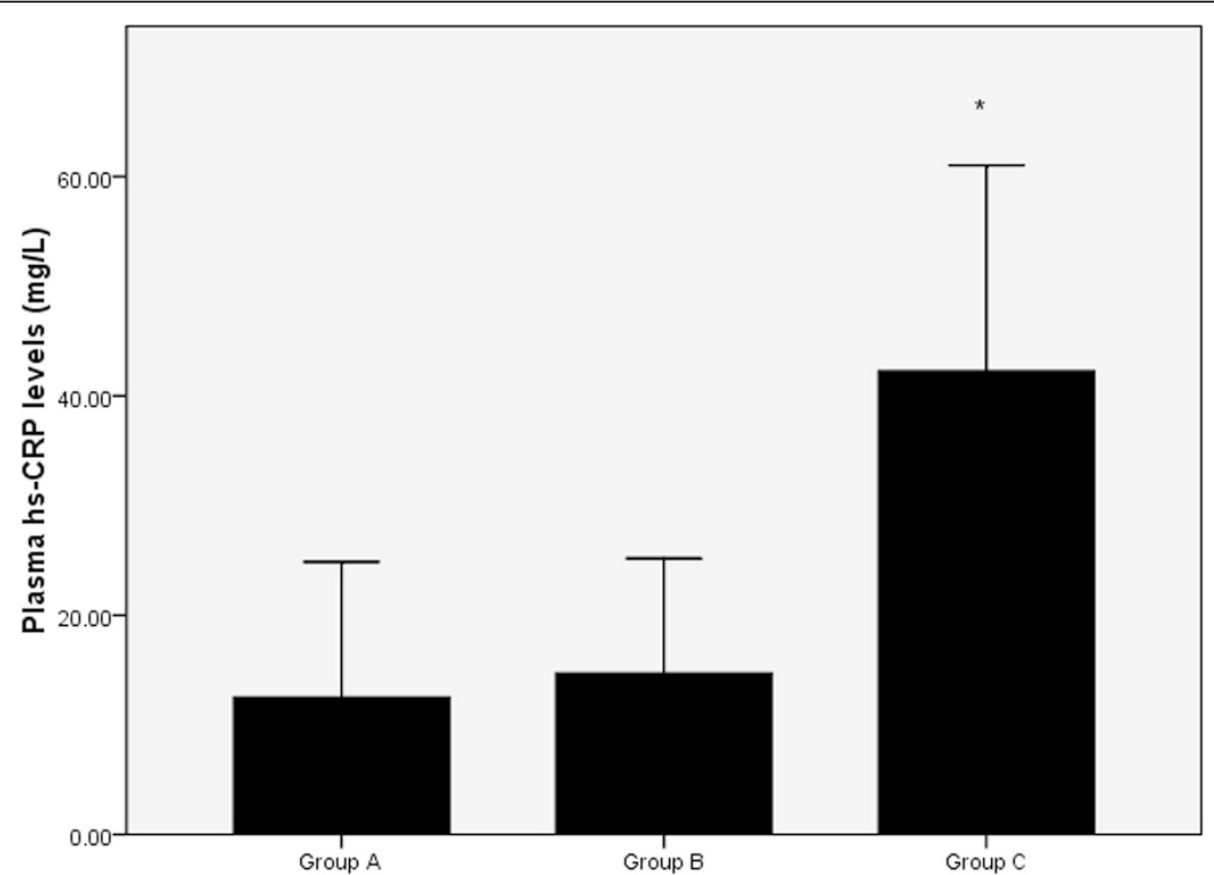

Fig. 2 The plasma hs-CRP levels in the three groups. ${ }^{*} p<0.05$ when compared to Group A or Group B 


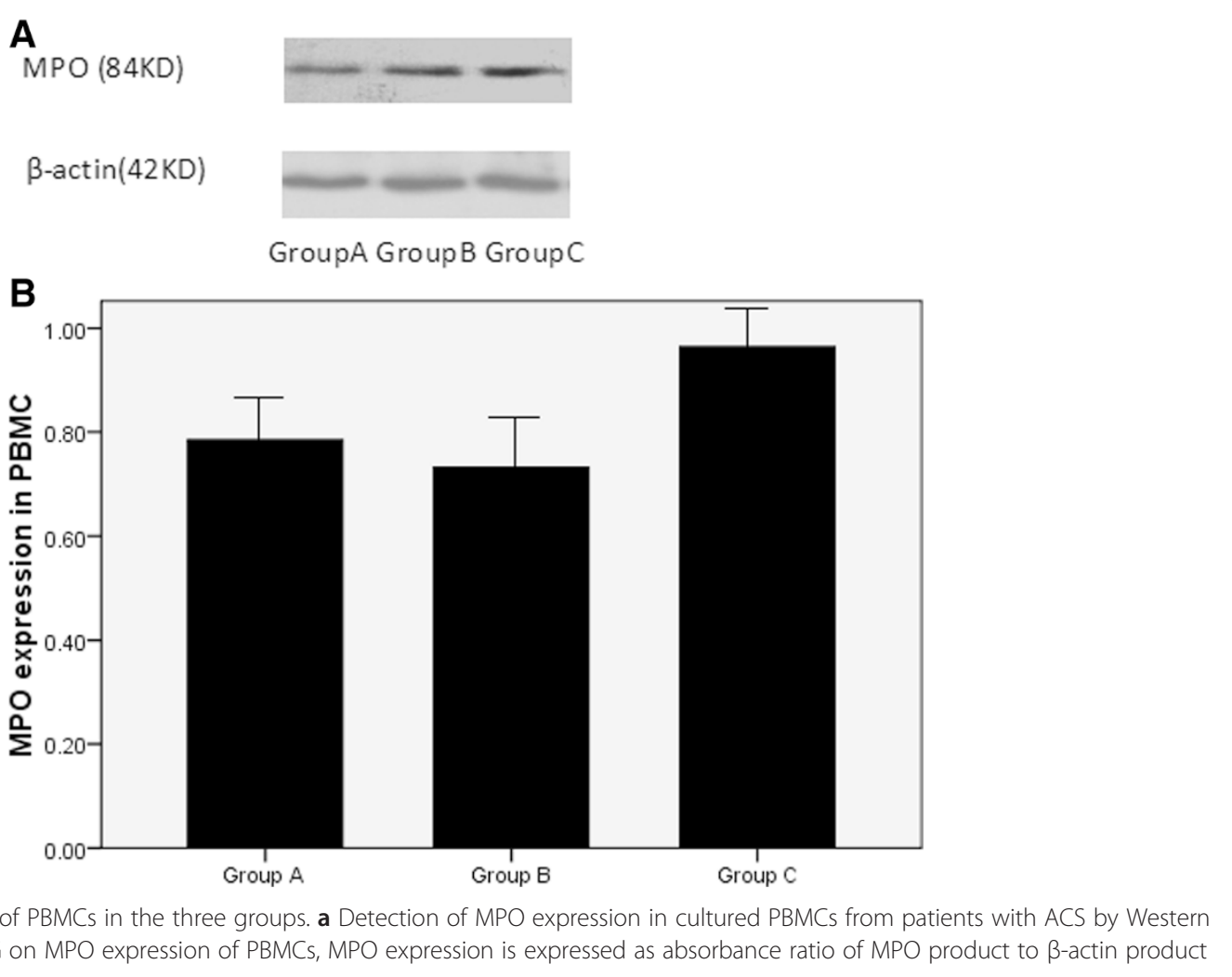

pathophysiology of atherosclerosis, but recent advances pointed out a contributory role of neutrophils during atherogenesis and plaque destabilization [1820]. Several proteins expressed and released by neutrophils emerged as possible biomarkers. MPO was abundantly expressed in neutrophil granules and partially released on neutrophils activation, leading to the plaque instability and vulnerability. In our study, the result also showed the positive association between the numbers of neutrophils and the FPG concentrations, this was consistent with the previous studies [19, 21-23].

In this study, we evaluated the relationship between the severity of coronary atherosclerosis and FPG, and the results showed that the FPG concentration increased with increasing Gensini score, suggesting that the FPG is also an indicator of the severity of the coronary artery lesion, which is consistent with the previous investigations $[24,25]$.

The majority of published studies evaluated the influence of APG on the prognosis of patients with ACS [26-28]. However, it is suggested that FPG may play a determining role. Otten et al. [29] showed that FPG is an independent predictor of adverse events in patients with ACS. In addition, Ravid et al. [30] and Soler et al. [31] demonstrated that FPG is a significant risk factor, and David Vivas et al. [6] have suggested that the FPG concentration is a better indicator of metabolic status than APG during the first few days of ACS. In addition, a significant relationship between high FPG and mortality within 30 days in non-diabetic patients with ACS was found by Suleiman et al. [32], with death usually occurring in patients with high FPG and normal APG values, or in those with high FPG and high APG, rather than in those with normal FPG. Moreover, for patients presenting an unfavorable clinical course during the first few hours of ACS, an increase in FPG may reflect a worse metabolic state and may be associated with more severe situations [33-35]; therefore, FPG may better represent the metabolic status of the patient with ACS. For clinicians caring for a patient with ACS, it is important to define the target below which the blood glucose levels should be maintained. The results of the study show that when the FPG levels are greater than $6.1 \mathrm{mmol} / \mathrm{l}$ (group C), the MPO levels and the hs-CRP levels are increased, indicating that clinicians may choose appropriate FPG values to avoid excessive inflammation in patients with ACS.

\section{Limitations}

An important limitation of this study is that there was a small number patients, no patients were administered an OGTT. As a result, it cannot be determined whether patients with no prior history of diabetes will become diabetics during observation. 


\section{Conclusions}

This study demonstrates that FPG values are positively correlated with plasma MPO levels, suggesting MPO may play a role in the proatherogenesis of high FPG. The exact roles of high FPG, MPO and their relation in the atherosclerosis have been completely clarified, it needs further investigation.

\section{Abbreviations}

FPG: Fasting plasma glucose; APG: Admission plasma glucose; MPO: Myeloperoxidase; ACS: Acute coronary syndrome; PBMCs: Peripheral blood mononuclear cells; hs-CRP: High sensitive $C$ reaction protein; BMI: Body mass index; TG: Triglyceride; TC: Total cholesterol; SBP: Systolic blood pressure; DBP: Diastolic blood pressure; LVEF: Left ventricular ejection fraction.

\section{Competing interests}

The authors declare that they have no competing interests.

\section{Authors' contributions}

$X Z$ and XX conceived of and designed the protocol. LD performed the experiments. QW analyzed the data. XX wrote the paper Manuscript. All the authors reviewed and approved the submitted version of the paper.

\section{Acknowledgements}

The authors are grateful to Xiaoli Peng for technical assistance.

\section{Received: 27 November 2014 Accepted: 13 August 2015}

\section{Published online: 25 August 2015}

\section{References}

1. Oswald GA, Corcoran S, Yudkin JS. Prevalence and risks of hyperglycaemia and undiagnosed diabetes in patients with acute myocardial infarction. Lancet. 1984:1(8389):1264-7.

2. Brindisi MC, Rabasa-Lhoret R, Chiasson JL. Postprandial hyperglycaemia: to treat or not to treat? Diabetes Metab. 2006;32(2):105-11.

3. Ishihara M, Kojima S, Sakamoto T, Asada Y, Tei C, Kimura K, et al. Acute hyperglycemia is associated with adverse outcome after acute myocardial infarction in the coronary intervention era. Am Heart J. 2005;150(4):814-20.

4. Ishihara M, Kagawa E, Inoue I, Kawagoe T, Shimatani Y, Kurisu S, et al. Impact of admission hyperglycemia and diabetes mellitus on short- and long-term mortality after acute myocardial infarction in the coronary intervention era. Am J Cardiol. 2007:99(12):1674-9.

5. Worthley MI, Holmes AS, Willoughby SR, Kucia AM, Heresztyn T, Stewart S, et al. The deleterious effects of hyperglycemia on platelet function in diabetic patients with acute coronary syndromes mediation by superoxide production, resolution with intensive insulin administration. J Am Coll Cardiol. 2007:49(3):304-10.

6. Vivas D, García-Rubira JC, González-Ferrer JJ, Núñez-Gil I, del Prado N, Fernández-Ortiz A, et al. Prognostic value of first fasting glucose measurement compared with admission glucose level in patients with acute coronary syndrome. Rev Esp Cardiol. 2008;61(5):458-64

7. Alvarenga MA, Oliveira CS, Chacra AR, Reis AF. Avaliação cardiovascular de pacientes diabéticos em ambulatório universitário. Arq Bras Endocrinol Metab. 2007;51(2):281-4.

8. Schraan BD, Reis AF. Doença cardiovascular e diabetes. Arq Bras Endocrinol Metab. 2007;51(2):151-2.

9. Nicholls SJ, Hazen SL. Myeloperoxidase and cardiovascular disease Arterioscler Thromb Vasc Biol. 2005;25(6):1102-11.

10. Fu X, Kassim SY, Parks WC, Heinecke JW. Hypochlorous acid oxygenates the cysteine switch domain of pro-matrilysin (MMP-7): a mechanism for matrix metalloproteinase activation and athero-sclerotic plaque rupture by myeloperoxidase. J Biol Chem. 2001;276(44):41279-87.

11. Sugiyama S, Kugiyama K, Aikawa M, Nakamura S, Ogawa H, Libby P. Hypochlorous acid, a macrophage product, induces endothelial apoptosis and tissue factor expression: involvement of myeloperoxidase-mediated oxidant in plaque erosion and thrombogenesis. Arterioscler Thromb Vasc Biol. 2004;24(7):1309-14
12. Baldus $S$, Heeschen $C$, Meinertz T, Zeiher AM, Eiserich JP, Münzel T, et al. Myeloperoxidase serum levels predict risk in patients with acute coronary syndromes. Circulation. 2003;108(12):1440-5.

13. Brennan ML, Penn MS, Van Lente F, Nambi V, Shishehbor MH, Aviles RJ, et al. Prognostic value of myeloperoxidase in patients with chest pain. $\mathrm{N}$ Engl J Med. 2003;349(17):1595-604.

14. Wong V, McLean M, Boyages S, Cheung NW. CRP levels following acute myocardial infarction: effect of insulininfusion and tight glycemic control. Diabetes Care. 2004;27(12):2971-3.

15. Esposito K, Nappo F, Marfella R, Giugliano G, Giugliano F, Ciotola M, et al. Inflammatory cytokine concentrations areacutely increased by hyperglycemia in humans: role ofoxidative stress. Circulation. 2002;106(16):2067-72.

16. Marfella R, Nappo F, De Angelis L, Paolisso G, Tagliamonte MR, Giugliano D. Hemodynamic effects of acute hyperglycemia in type 2 diabetic patients. Diabetes Care. 2000;23(5):658-63.

17. Ceriello A, Quagliaro L, D'Amico M, Di Filippo C, Marfella R, Nappo F, et al. Acute hyperglycaemia induced nitrotyrosine formation and apoptosis in perfused heart from rats. Diabetes. 2002;51(4):1076-82.

18. Baetta R, Corsini A. Role of polymorphonuclear neutrophils in atherosclerosis: current state and future perspectives. Atherosclerosis. 2010;210(1):1-13.

19. Matsumura T, Taketa K, Motoshima H, Senokuchi T, Ishii N, Kinoshita H, et al. Association between circulating leukocyte subtype counts and carotid intima-media thickness in Japanese subjects with type 2 diabetes. Cardiovasc Diabetol. 2013;27(12):177.

20. Drechsler M, Megens RT, van Zandvoort M, Weber C, Soehnlein O. Hyperlipidemia-triggered neutrophilia promotes early atherosclerosis. Circulation. 2010;122(18):1837-45.

21. Yilmaz H, Ucan B, Sayki M, Unsal I, Sahin M, Ozbek M, Delibasi T. Usefulness of the neutrophil-to-lymphocyte ratio to prediction of type 2 diabetes mellitus in morbid obesity. Diabetes Metab Syndr. 2014; 19. doi: 10.1016/ j.dsx.2014.04.009.

22. Shiny A, Bibin YS, Shanthirani CS, Regin BS, Anjana RM, Balasubramanyam $M$, et al. Association of neutrophil-lymphocyte ratio with glucose intolerance: an indicator of systemic inflammation in patients with type 2 diabetes. Diabetes Technol Ther. 2014;16(8):524-30.

23. Ionita MG, van den Borne $\mathrm{P}$, Catanzariti LM, Moll FL, de Vries JP, Pasterkamp $\mathrm{G}$, et al. High neutrophil numbers in human carotid atherosclerotic plaques are associated with characteristics of rupture-prone lesions. Arterioscler Thromb Vasc Biol. 2010;30(9):1842-8.

24. Gui MH, Li X, Lu ZQ, Gao X. Fasting plasma glucose correlates with angiographic coronary artery disease prevalence and severity in Chinese patients without known diabetes. Acta Diabetol. 2013;50(3):333-40.

25. Karan A, Güray Y, Güray U, Demirkan B, Astan R, Baysal E, et al. Mean platelet volume and the extent of coronary atherosclerosis in patients with stable coronary artery disease. Turk Kardiyol Dern Ars. 2013;41 (1):45-50

26. Konstantinou DM, Chatzizisis YS, Louridas GE, Parcharidis GE, Giannoglou GD. Non-diabetic hyperglycaemia correlates with angiographic coronary artery disease prevalence and severity. Diabetes Metab. 2010;36(5):402-8.

27. Quadros AS, Sarmento-Leite R, Bertoluci M, Duro K, Schmidt A, De Lucca Jr $\mathrm{G}$, et al. Angiographic coronary artery disease is associated with progressively higher levels of fasting plasma glucose. Diabetes Res Clin Pract. 2007;75(2):207-13.

28. Kosiborod M, Rathore SS, Inzucchi SE, Masoudi FA, Wang Y, Havranek EP, et al. Admission glucose and mortality in elderly patients hospitalized with acute myocardial infarction: implications for patients with and without recognized diabetes. Circulation. 2005;111(23):3078-86.

29. Otten R, Kline-Rogers E, Meier DJ, Dumasia R, Fang J, May N, et al. Impact of pre-diabetic state on clinical outcomes in patient with acute coronary syndrome. Heart. 2005;91(11):1466-8.

30. Ravid M, Berkowicz M, Sohar E. Hyperglycemia during acute myocardial infarction: a six-year follow-up study. JAMA. 1975;233(7):807-9.

31. Soler NG, Frank S. Value of glycosylated haemoglobin measurements after acute myocardial infarction. JAMA. 1981;246:1690-93.

32. Suleiman $M$, Hammerman $H$, Boulos $M$, Kapeliovich MR, Suleiman A, Agmon $Y$, et al. Fasting glucose is an important independent risk factor for 30-day mortality in patients with acute myocardial infarction: a prospective study. Circulation. 2005;111(6):754-60. 
33. Deedwania P, Kosiborod M, Barrett E, Ceriello A, Isley W, Mazzone T, et al. Hyperglycemia and acute coronary syndrome: a scientific statement from the American heart association diabetes committee of the council on nutrition, physical activity, and metabolism. Circulation. 2008;117(12):1610-9.

34. Kosiborod M. Blood glucose and its prognostic implications in patients hospitalised with acute myocardial infarction. Diab Vasc Dis Res. 2008; $5(4): 269-75$

35. Ceriello A. Cardiovascular effects of acute hyperglycaemia: pathophysiological underpinnings. Diab Vasc Dis Res. 2008;5(4):260-8.

\section{Submit your next manuscript to BioMed Central} and take full advantage of:

- Convenient online submission

- Thorough peer review

- No space constraints or color figure charges

- Immediate publication on acceptance

- Inclusion in PubMed, CAS, Scopus and Google Scholar

- Research which is freely available for redistribution 